\title{
Health benefits and costs of weight-loss dietary counselling by nurses in primary care: a cost-effectiveness analysis
}

\author{
Christine L Cleghorn*, Nick Wilson, Nisha Nair, Giorgi Kvizhinadze, Nhung Nghiem, \\ Melissa McLeod and Tony Blakely \\ Burden of Disease Epidemiology, Equity and Cost-Effectiveness Programme, University of Otago, PO Box 7343, \\ Newtown, Wellington 6242, New Zealand
}

Submitted 25 October 2018: Final revision received 7 May 2019: Accepted 2 July 2019: First published online 14 October 2019

\begin{abstract}
Objective: We aimed to estimate the cost-effectiveness of brief weight-loss counselling by dietitian-trained practice nurses, in a high-income-country case study.

Design: A literature search of the impact of dietary counselling on BMI was performed to source the 'best' effect size for use in modelling. This was combined with multiple other input parameters (e.g. epidemiological and cost parameters for obesity-related diseases, likely uptake of counselling) in an established multistate life-table model with fourteen parallel BMI-related disease life tables using a $3 \%$ discount rate.

Setting: New Zealand (NZ).

Participants: We calculated quality-adjusted life-years (QALY) gained and healthsystem costs over the remainder of the lifespan of the NZ population alive in 2011 ( $n 4.4$ million).

Results: Counselling was estimated to result in an increase of 250 QALY (95\% uncertainty interval -70, 560 QALY) over the population's lifetime. The incremental cost-effectiveness ratio was 2011 \$NZ 138200 per QALY gained (2018 \$US 102 700). Per capita QALY gains were higher for Māori (Indigenous population) than for non-Māori, but were still not cost-effective. If willingness-to-pay was set to the level of gross domestic product per capita per QALY gained (i.e. 2011 \$NZ 45000 or 2018 \$US 33 400), the probability that the intervention would be cost-effective was $2 \%$.

Conclusions: The study provides modelling-level evidence that brief dietary counselling for weight loss in primary care generates relatively small health gains at the population level and is unlikely to be cost-effective.
\end{abstract}

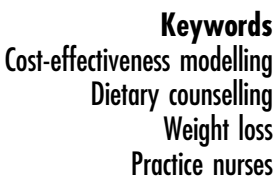

High BMI is an important risk factor for disease globally ${ }^{(1)}$. Those who are obese have higher rates of CHD, stroke, diabetes, osteoarthritis and various cancers ${ }^{(2)}$. As with many other high-income countries, rates of obesity have risen in New Zealand (NZ); $28 \%$ of adults were obese in 2011/12, up from $19 \%$ in $1997^{(3)}$. A wide range of interventions aimed at decreasing BMI in such countries will probably be needed if this trend is going to be reversed.

Dietary advice to reduce energy intake has been shown to be effective in helping people lose weight ${ }^{(4-6)}$. In a meta-analysis ${ }^{(6)}$ of forty-six trials, where those giving dietary advice were not limited to health professionals, BMI was $1.9(95 \%$ CI $2.3,1.5)$ units lower at 12 months in the treatment groups compared with usual care. In a second meta-analysis, diet interventions (delivered by a wide range of health professionals) focusing on reducedenergy diets with behavioural strategies resulted in an average of $4.9 \mathrm{~kg}$ in weight loss after 6 months, compared with advice alone ${ }^{(5)}$. However, a meta-analysis on the effect of brief behavioural weight-management programmes for adults conducted in everyday contexts (more details in the 'Methods' section below) showed a decrease of $0.45 \mathrm{~kg}$, with the $95 \%$ CI including the null $(-0.43$, $1.34 \mathrm{~kg}$ ), at 12 months compared with the control group ${ }^{(4)}$.

There has been mixed evidence on the effectiveness of practice nurses in the primary-care setting providing 


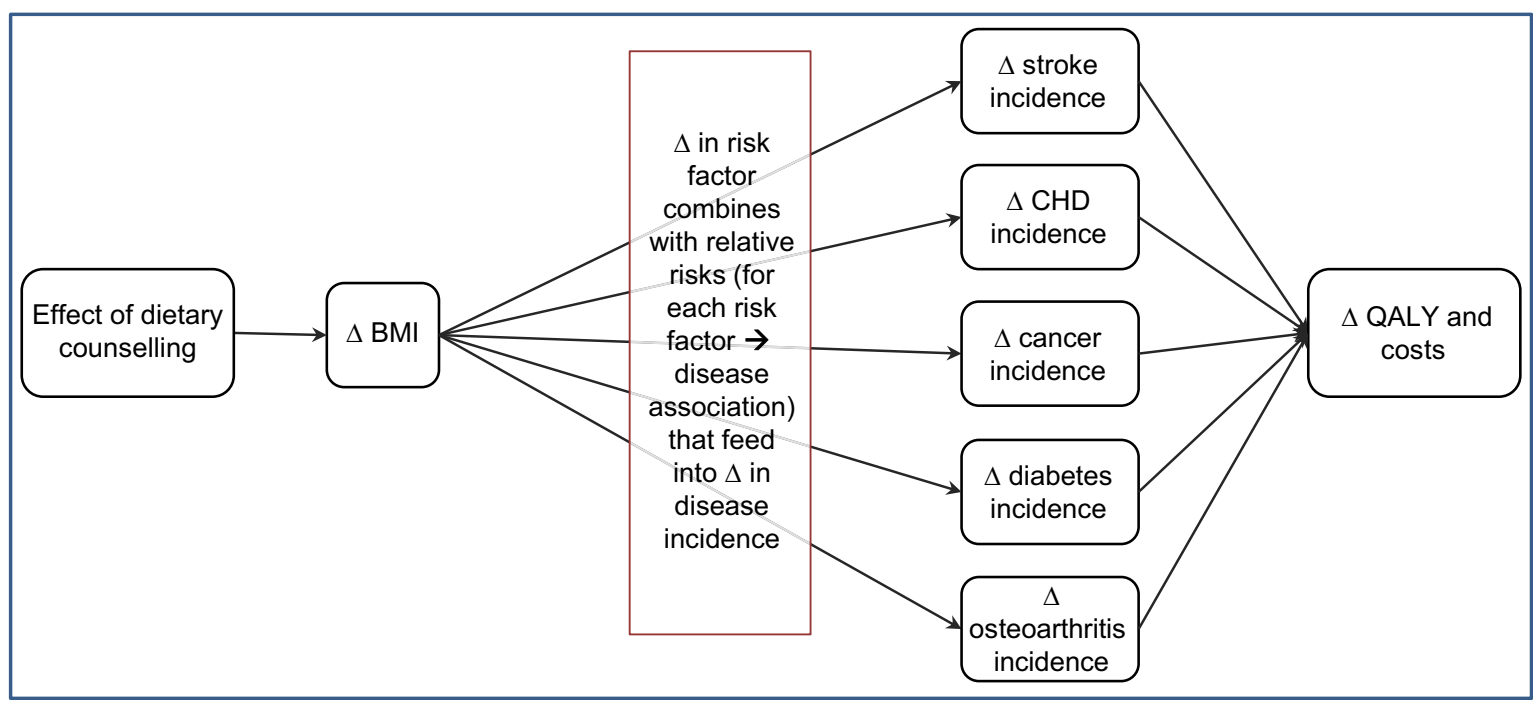

Fig. 1 (colour online) Conceptual diagram of the diet multistate life-table model used in the present modelling ( $\Delta$, change; QALY, quality-adjusted life-year)

dietary advice. A literature review on nursing practice in obesity management in the UK concluded that, under current practice, at most $10 \%$ of those following a nurseled support programme were currently achieving clinically significant weight loss ${ }^{(7)}$. An international review concluded that there was evidence to show nurse-delivered lifestyle interventions impacted positively on outcomes associated with the prevention of chronic disease, including weight loss, but quantification of the effectiveness was not possible due to the heterogeneity of the included studies ${ }^{(8)}$.

There is little research examining the cost-effectiveness of weight-loss advice interventions generally, but what is available suggests they are often cost-effective ${ }^{(9-11)}$. For example, a diabetes prevention study found that a combined intervention of advice from a general practitioner (GP) and diet and behavioural therapy cost the equivalent of 2011 \$NZ 1430-3710 for each additional year of life saved ${ }^{(9)}$. A modelling study estimated the Dietary Approaches to Stop Hypertension (DASH) diet to have an incremental cost-effectiveness ratio of 2011 \$NZ 11900 per disability-adjusted life-year averted and a less-intensive low-fat diet programme to have an an incremental cost-effectiveness ratio of 2011 \$NZ 12900 per disability-adjusted life-year averted ${ }^{(11)}$. However, the costeffectiveness of brief dietary advice in primary care is not well covered by existing literature.

Given this background, the primary aim of the present study was to estimate the future impact on the magnitude and timing of health gains and changes in health-system expenditure from an intervention employing practice nurses trained by dietitians to give dietary advice to overweight or obese adults in a high-income country setting: New Zealand. The 'business-as-usual' comparator was usual care, which is defined as that provided by a health professional such as a GP and which does not typically include dietary counselling for weight loss.

\section{Methods}

\section{Overview}

Main outputs from this modelling were incremental health gain in QALY and health-system costs in 2011 NZ dollars (\$NZ) between the dietary counselling intervention and business-as-usual. Both health gain and costs were discounted at $3 \%$, with $0 \%$ and $6 \%$ used in scenario analyses. This modelling takes a health-system perspective, it excludes co-payments by patients and assumes that the intervention is fully funded by the health system. Benefits and costs are modelled over a lifetime horizon. The intervention was modelled as a one-off intervention (i.e. $1 \mathrm{~h}$ appointment with a practice nurse, with followup as needed; an average of $2 \mathrm{~h}$ per person) in the target population of overweight and obese adults.

The intervention effect was captured in the model through changes in weight from dietary counselling leading to change in average BMI, and then through population impact fractions (combining this change in BMI with relative risks for the associations between BMI and BMI-related disease) to alter disease incidence which results in changes in QALY and health-system costs.

A diet multistate life-table model (MSLT) was built from an established tobacco control MSLT model (using many of the same diseases), from which we have published work previously ${ }^{(12-15)}$. This new diet model has itself already been used for studying a number of dietary interventions ${ }^{(16,17)}$. The conceptual diagram of this diet model is shown in Fig. 1 and is described further in an online technical report ${ }^{(18)}$ (see Supplemental File 2).

The diet MSLT model was used to simulate the entire NZ population that was alive in 2011 over their remaining lifetimes. This model is structured as a main life table with projected all-cause mortality and morbidity rates by sex and 
age for Māori (Indigenous New Zealanders) and non-Māori with fourteen BMI-related diseases running in parallel (i.e. CHD, stroke, type 2 diabetes, osteoarthritis and multiple cancers: endometrial, kidney, liver, oesophageal, pancreatic, thyroid, colorectal, breast, ovarian and gallbladder). The proportion of the NZ population in each parallel disease state is a function of the disease incidence, case fatality and remission (the latter in cancers only) of those diseases.

\section{Business-as-usual input parameters}

All input parameters, specified by sex, age and ethnicity unless stated differently, are shown in Supplemental Table S1. Incidence, prevalence and case-fatality rates in 2011 are included for each disease. Remission was specified for cancers and set to zero for the chronic conditions of CHD, stroke, type 2 diabetes and osteoarthritis. Morbidity was quantified for each disease. This was calculated as prevalent years of life lived with disability from the NZ Burden of Disease Study, divided by the population count.

Individually linked data for publicly funded (and some privately funded) health events occurring in 2006-2010 were used to calculate sex- and age-specific health-system costs in 2011 \$NZ. These costs included hospitalisations, inpatient procedures, outpatients, pharmaceuticals, laboratories and expected primary-care usage. Costs that were assigned in the model fell into the following three categories: (i) sexand age-specific annual cost of a citizen who does not have a BMI-related disease and is not in the last 6 months of his/her life; (ii) disease-specific excess costs for people in the first year of diagnosis, the last 6 months of life if dying of the given disease, and otherwise prevalent cases of each disease in the model; and (iii) the costs associated with the last 6 months of life if dying from a disease not in the model.

\section{Intervention parameters}

\section{Intervention specification}

The intervention consists of training and employing practice nurses to give dietary advice to the target population in an individual setting. This consists of an initial appointment (60 min) and follow-up in person, by telephone or by email as needed (an average of $1-3 \mathrm{~h}$ of contact per patient in total, modelled as an average of $2 \mathrm{~h}$ ( $120 \mathrm{~min})$ per patient). The intervention was modelled as a one-off intervention that occurred within the baseline year (2011).

The target population for this intervention was $\mathrm{NZ}$ adults who are overweight, defined as having a BMI of $25-30 \mathrm{~kg} / \mathrm{m}^{2}$ (varies by age and ethnicity, but an average of $34 \%$ of the NZ adult population), or obese, defined as having a BMI of $>30 \mathrm{~kg} / \mathrm{m}^{2}$ (average of $39 \%$ of the NZ adult population in 2008/09 $\left.{ }^{(19)}\right)$. For the model, we specified that overweight and obese adults would be recruited by their GP through the existing national programme of 'Heart and Diabetes Checks' which already collects data on height, weight and waist circumference ${ }^{(20)}$.

\section{Referral rate}

The existing 'Heart and Diabetes Checks' programme in 2011 in NZ targeted Māori, Pacific and Indo-Asian men aged $>35$ years and women aged $>45$ years, European men aged $>45$ years and European women aged $>55$ years, and people who have a family history of heart problems.

The proportion of the population likely to receive this intervention and how this model input is calculated are presented in Fig. 2. On average, $90 \%$ (95\% uncertainty interval $80,97 \%$ ) of eligible adults had their diabetes and CVD risk assessed in the five years leading up to $2015^{(21)}$. We used this figure as an estimate for the proportion of the target population that would be identified by GPs as eligible for the intervention.

The proportion of the target population that would be likely to be referred to practice nurses for weight-loss advice (60\%; $95 \%$ uncertainty interval 35, 82\%) was estimated from a European survey of $\mathrm{GPs}^{(22)}$. This survey found that for a scenario of a 52-year-old man with no other risk factors, $62 \%$ of GPs reported advising overweight patients to lose weight and $59 \%$ reported doing the same for a scenario of a 59-year-old woman with no other risk factors.

\section{Uptake rate}

We then estimated what proportion of those referred to a dietary counselling appointment with a practice nurse would be likely to take up this opportunity based on a study by Wee et al. ${ }^{(23)}$. That study assessed patients' readiness to lose weight and to change a number of weight-related behaviours. Wee et al. classified respondents into different stages for each behaviour: (i) pre-contemplative and (ii) contemplative, and then three advanced stages of change: (iii) preparation (thinking about changing in the next month), (iv) action (attempting change currently) and (v) maintenance (changed behaviour and attempting to maintain change). In their study $46 \%$ of overweight and $53 \%$ of obese adults were at one of the three advanced stages of change to lose weight, improve diet and increase exercise. From these data we estimated that $49.4 \%$ (a weighted average of $46 \%$ and $53 \%$; $95 \%$ uncertainty interval 40, 59\%) of the overweight population referred to this intervention would be likely to take it up.

\section{Effect size}

We undertook a literature review to identify the 'best' estimate of how much dietitian-trained practice nurses would impact BMI on 3 March 2017 in 'Ovid MEDLINE(R) <1996 


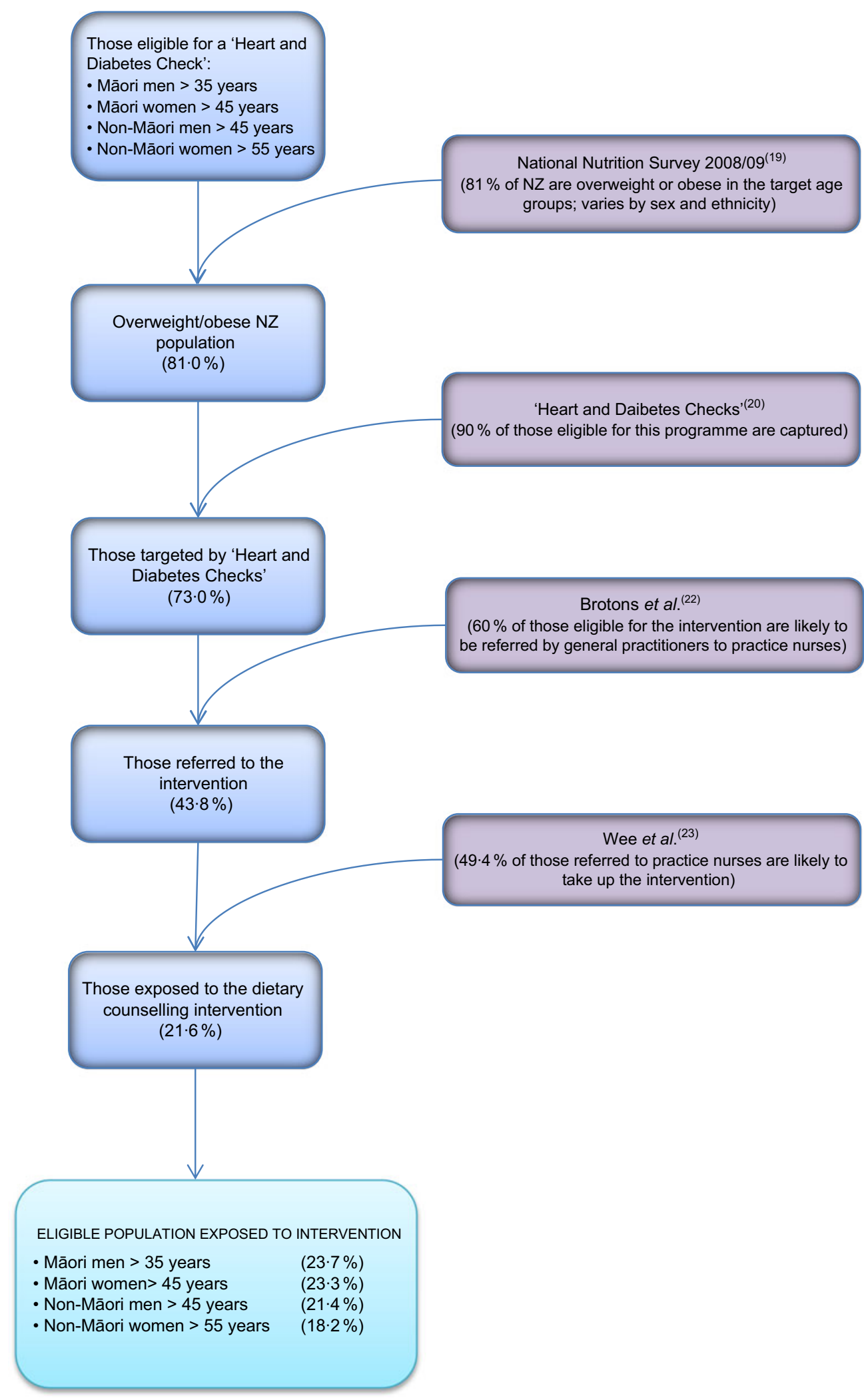

Fig. 2 (colour online) Flow diagram illustrating the targeting of the practice-nurse-delivered dietary counselling intervention in the New Zealand (NZ) adult population 
to Present with Daily Update'. We used the following search terms:

\section{diet\$.mp. AND}

counsel\$.mp OR advice.mp OR advis\$.mp AND

weight.mp OR BMI.mp. OR body mass index.mp AND

effectiveness.mp. AND

primary care.mp. OR health care.mp. OR healthcare.mp

From this search we identified sixteen papers of which eight were randomised controlled trials, one was a prospective cohort study, four were reviews, two were duplicated papers and one was a meta-analysis.

We carried out additional searches using Google Scholar and the reference lists of retrieved studies but no papers were found that more closely aligned with the current intervention than the identified meta-analysis. That meta-analysis, by Hartmann-Boyce et al. ${ }^{(4)}$, investigated behavioural weight-management programmes for adults conducted in everyday contexts. It included data from five interventions delivered by primary-care teams in four cases and trained lay people in the fifth case. In four of the included study arms the advice was given individually, including one Internet-based intervention, while in the other study advice was given in a group setting. The total contact time varied from 4 to $24 \mathrm{~h}$ over 3 to 24 months. Inclusion criteria for interventions specified that they were structured weight-management programmes, that they incorporated diet, physical activity and a behaviour change strategy, that they were available outside a trial context and that they involved multiple contacts. The meta-analysis showed a small weight reduction, albeit not at a statistically significant level (mean difference $=-0.45 \mathrm{~kg}, 95 \% \mathrm{CI}-1.34,0.43 \mathrm{~kg}$ ), compared with the control groups.

Due to the average contact time in the meta-analysis being more than that we considered realistic to model for the NZ primary-care setting (with its resource constraints), the effect size was scaled down. So using the original effect sizes in the five included studies, an average per minute weight decrease was calculated and then multiplied by $120 \mathrm{~min}$ to give an effect size of $-0.34 \mathrm{~kg}$. The $0.34 \mathrm{~kg}$ reduction in weight was then converted to a modelled 0.11 BMI unit decrease in men and a 0.13 unit decrease in women over 2 years for those receiving the intervention (using average heights for the four sex by ethnic groups). The uncertainty reported in the meta-analysis (95\% CI $-1.34,0.43 \mathrm{~kg}$ ) was scaled by a ratio of $0.34 / 0.45$ to (95\% CI $-1.01,0.32 \mathrm{~kg}$ ) and included in the modelled decrease. When this effect was averaged over the overweight and obese eligible population (i.e. allowing for coverage, etc.), this reduced to a change of $-0.03 \mathrm{BMI}$ units per person.
The rate at which the weight loss attenuated over time was based on Dansinger et al. ${ }^{(6)}$ who found that BMI increased by $0.03 \mathrm{BMI}$ units/month post-dietary counselling from an initial BMI decrease of 1.9 units. Evidence on how weight regain differs by magnitude of initial weight loss is currently limited, so we used this 0.03 BMI units/ month as an estimate of how the modelled weight loss would decay post-intervention. With such a small initial effect size, the BMI decrease returned to zero approximately 5 months into the year after the intervention.

\section{Relative risks, population impact fractions and time lags}

The change in BMI was then combined with the diseasespecific relative risks listed in Supplemental Tables S3 and S4, through population impact fractions (see equation (1)) which alter the incidence of BMI-related diseases:

$$
P I F=\frac{\sum_{c=1}^{n} p_{c} R R_{c}-\sum_{c=1}^{n} p_{c} R R_{c}^{*}}{\sum_{c=1}^{n} p_{c} R R_{c}},
$$

where PIF is population impact fraction; $p_{c}$ is the proportion of the population in category $c ; R R_{c}$ is the relative risk for category $c$; and $R R_{c}^{*}$ is the risk ratio for category $c$ after the intervention, i.e. the 'shifted' relative risk.

A change in BMI will not have an instantaneous impact on disease incidence, due to time lags in disease aetiology. It is poorly understood what the time lags are, but that they exist (especially for cancers) is without doubt. Therefore to not include time lags would be to incorrectly estimate health gains (and costs/cost savings) as occurring too soon. We therefore specified a time window for BMI impact on cancers of between 10 and 30 years, and for CHD, stroke, diabetes and osteoarthritis of $0-5$ years (with uncertainty about start and endpoints of these windows as in Supplemental Table S1).

\section{Intervention costs}

Costs of the intervention were calculated as practice nurse time (Table 1), dietitian time for training and support of the practice nurses, and additional costs including mail-outs and resources.

The health-system cost was the combination of the intervention costs and the difference in projected future health-system expenditure resulting from changes in disease incidence due to the dietary counselling (and including extra health-system costs from any longer life attributable to the intervention).

\section{Modelling and analysis}

An Ersatz add-in ${ }^{(24)}$ to Microsoft Excel was used to incorporate parameter uncertainty and run the multiple sex by age by ethnic cohorts through the model 2000 times each. Each iteration involved a random draw from the probability density function about the parameters, specified with uncertainty, in Supplemental Tables S1 and S2. The main 
Table 1 Intervention costs used in the modelled intervention

\begin{tabular}{|c|c|c|}
\hline Cost component & Details & Cost (2011 \$NZ) \\
\hline Practice nurse time & $\begin{array}{l}\text { The main component of the intervention cost was practice } \\
\text { nurse time, both for the initial appointment and follow-up } \\
\text { contacts. We assumed that this cost would be covered by } \\
\text { the health system rather than being paid for by the } \\
\text { patients. The hourly rate for a Step } 5 \text { registered nurse in } \\
\text { primary care was } \$ N Z 28.54 \text { excluding overheads in } \\
2011^{(34)} \text {. Including } 50 \% \text { overheads brings practice nurse } \\
\text { costs to } \$ N Z 42 \cdot 81 / \mathrm{h} \text {. Practice nurse time for their own } \\
\text { training in providing dietary counselling was also included } \\
\text { at } 10 \mathrm{~h} \text { per nurse at the same rate as above }\end{array}$ & $\begin{array}{l}\text { It was assumed that practice nurses would commit } \\
\text { between } 1 \text { and } 3 \mathrm{~h} \text { to each patient (costed } \\
\text { assuming an average of } 2 \mathrm{~h} \text { each): } \\
\text { \$NZ } 36159124 \text { (\$NZ } 87 \text { per patient, } 417321 \\
\text { targeted patients) }\end{array}$ \\
\hline $\begin{array}{l}\text { Dietitian time (for } \\
\text { training and } \\
\text { support) }\end{array}$ & $\begin{array}{l}\text { Dietitian time for training practice nurses and ongoing } \\
\text { contact with practice nurses if needed was also costed. } \\
\text { The hourly rate for a dietitian to train the practice nurses } \\
\text { was as per dietitian costing for DHB of } \$ N Z 115 \cdot 89^{(35)} \text {, } \\
\text { adjusted from } 2012 / 13 \text { to } 2011 / 12 \text {, as per the BODE } \\
\text { Costing Protocol( } 36 \text { ). Based on an estimate by a NZ } \\
\text { dietitian, it was assumed that } 8 \mathrm{~h} \text { of a dietitian's time } \\
\text { would be required to train a small group ( } n \leq 4) \text { of } \\
\text { practice nurses for this intervention. An additional } 2 \mathrm{~h} \text { per } \\
\text { practice nurse for ongoing training and support from the } \\
\text { dietitian should be allowed. Based on an estimate from } \\
\text { the Ministry of Health on the number of PHO 'GP } \\
\text { practices' submitting enrolment registers (of } n 1020) \text {, it } \\
\text { was assumed that this training would be necessary for } \\
1000 \text { practice nurses. The Ministry of Health key } \\
\text { informant indicated uncertainty around the registered } \\
\text { practices as a 'GP practice' is not a well-defined term and } \\
\text { each is used differently by different PHO. For example, } \\
\text { some PHO will submit a register for each doctor at a } \\
\text { medical centre while others will combine the patients } \\
\text { enrolled at a number of sites and submit as a single } \\
\text { 'practice', and there are a number of practices outside the } \\
\text { PHO funding structure that offer GP services alongside } \\
\text { more specialist services (e.g. sports medicine). We } \\
\text { therefore included wide uncertainty around total costs } \\
\text { (see below for uncertainty) }\end{array}$ & \$NZ 463560 (\$NZ 464 per nurse) \\
\hline Additional costs & $\begin{array}{l}\text { Additional costs were those associated with mail-outs to } \\
\text { patients regarding an appointment with practice nurses } \\
\text { as well as the distribution of relevant resources to the } \\
\text { patient at } \$ N Z 4 \text { per patient (\$NZ1669284). Costs to the } \\
\text { individual practices for administrator time and resources } \\
\text { was factored in by including overheads on nurse salaries }\end{array}$ & \$NZ1 669284 \\
\hline $\begin{array}{l}\text { Total intervention } \\
\text { costs }\end{array}$ & $\begin{array}{l}\text { Uncertainty: estimated at } \mathrm{SD}= \pm 20 \% \text { of the point estimate, } \\
\text { gamma distribution }\end{array}$ & \$NZ38 291968 \\
\hline
\end{tabular}

DHB, district health board; PHO, primary health organisation; GP, general practitioner.

results produced by the model were incremental QALY and net health-system costs. Results for the base case are presented for the total population and by sex and ethnicity (Māori and non-Māori).

Given the uncertainty in the effect size, we also used a net monetary benefit (NMB) approach to estimate the probability that the intervention was cost-effective for varying thresholds at which society might be willing to 'pay' for a QALY (presented in Fig. 3). The NMB is given by:

$$
N M B=\lambda \times \Delta Q-\Delta C,
$$

where $\lambda$ is the threshold (e.g. $2011 \$ N Z 45000$ or 2018 \$US 33400 per QALY); $\Delta Q$ is the incremental health gain/loss; and $\Delta C$ is the incremental cost.
The NMB is calculated for a range of $\lambda$ for the outputs of each iteration of the model, meaning that across all model iterations for a given $\lambda$ one can calculate the proportion of times the intervention might be considered 'cost-effective' (i.e. proportion of iterations where $\mathrm{NMB}>0$ ).

For parameters contributing to the uncertainty of the results, tornado plots for the NMB (Fig. 4), QALY gains (Supplemental Fig. S1) and health-system costs (Supplemental Fig. 2) are presented. The numbers presented in these figures were calculated by setting the relevant parameters to their $2 \cdot 5$ th and 97.5 th percentiles and running the model with uncertainty switched off. These tornado plots were designed to help identify targets for future research that would reduce uncertainty of key parameters used in the costeffectiveness modelling and thereby increase certainty in decision making. 


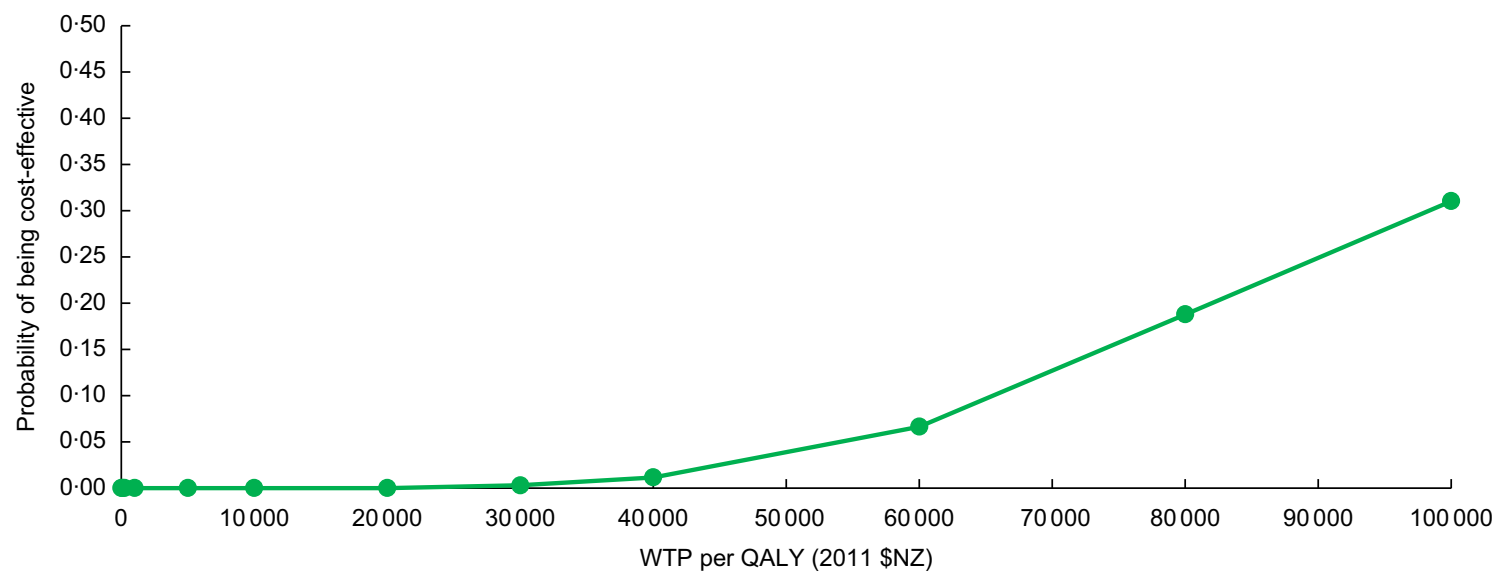

Fig. 3 (colour online) Cost-effectiveness acceptability curve for practice-nurse-delivered dietary counselling for weight loss in the New Zealand adult population (WTP, willingness-to-pay; QALY, quality-adjusted life-year)

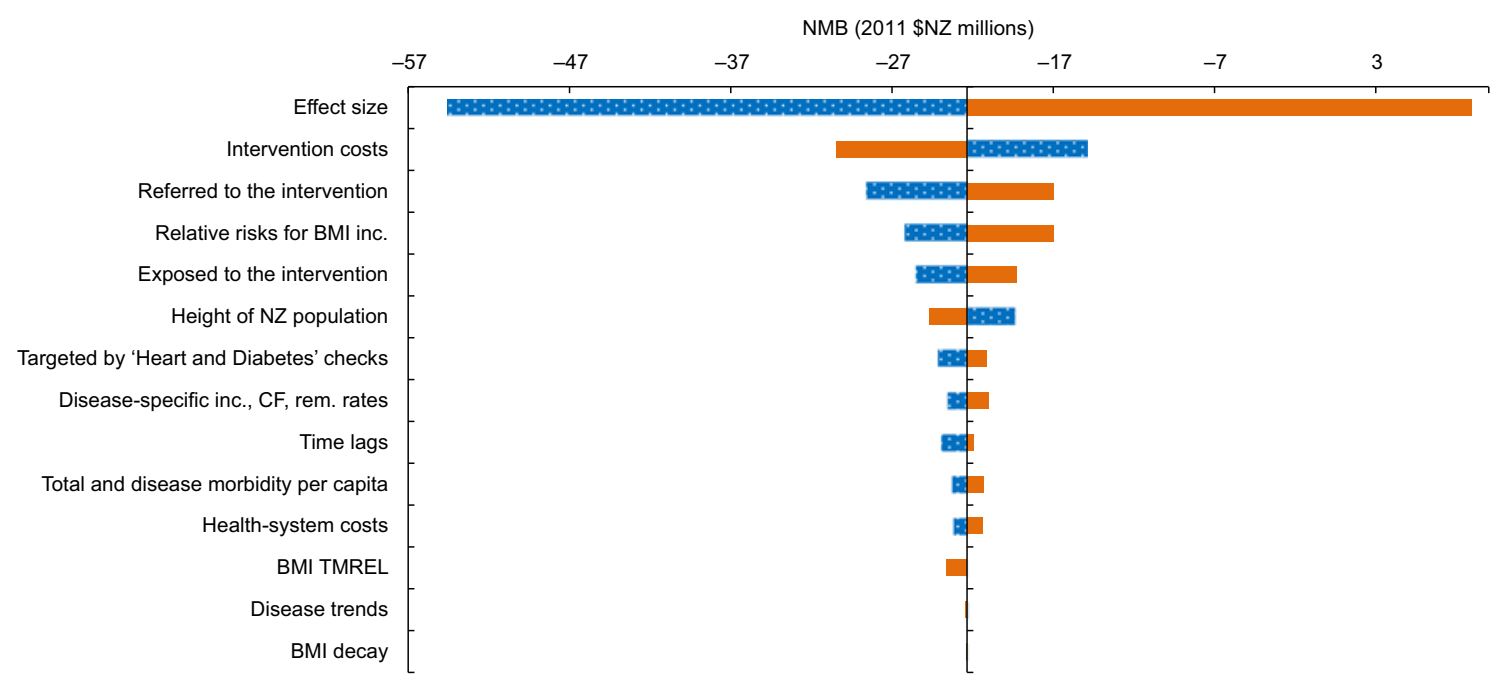

Fig. 4 (colour online) Tornado plot showing the major drivers of uncertainty in the net monetary benefit (NMB) analysis (using 2011 \$NZ 45000 as the threshold) for the New Zealand (NZ) adult population as a result of individual dietary counselling: 2 , incremental cost for the 2.5th percentile of the input parameter (low); $\square$, incremental cost for the 97.5th percentile of input parameter (high) (inc., incidence; CF, case fatality; rem., remission; TMREL, Theoretical Minimum Risk Exposure Level)

\section{Scenario and sensitivity analyses}

Māori have higher background mortality and morbidity, resulting in a lesser 'envelope' for potential health gains which disadvantages Māori in the analysis. Therefore, an equity analysis whereby non-Māori all-cause mortality and population morbidity rates are used for Māori ${ }^{(25)}$ was conducted (Table 2).

A scenario analysis using the original effect size from the Hartmann-Boyce et al. ${ }^{(4)}$ meta-analysis was also included in Table 3.

In the base case, weight loss occurred in the first year and then began a steep decay. In order to explore the impact of the decay rate used in the base case, we ran a scenario analysis simulating a theoretical situation where all weight lost with the intervention was maintained over the subsequent course of the participants' lifetimes.
We also ran sensitivity analyses varying the discounting rate from $3 \%$ (to $0 \%$ and $6 \%$ ).

\section{Results}

The total health gain for the NZ population estimated for dietary counselling was 250 QALY ( $95 \%$ uncertainty interval -70, 560 QALY; see Table 2). Net health-system costs were an extra \$NZ33.9 million (95\% uncertainty interval \$NZ $24 \cdot 1$ million, \$NZ 43.8 million; 2011 \$NZ real dollars or 2018 \$US 25.2 million). Based on the expected value results presented in Table 2 , the incremental cost-effectiveness ratio for dietary counselling was estimated to be 2011 \$NZ 138200 per QALY gained (or 2018 \$US 102700 ).

Figure 3 shows the cost-effectiveness acceptability curve for the adult population as a whole, illustrating the 
Table 2 Modelled health gains (quality-adjusted life-years (QALY)) and net health-system costs among the New Zealand (NZ) adult population alive in 2011 for the weight-loss counselling intervention delivered by practice nurses in primary-care settings*

\begin{tabular}{|c|c|c|c|c|c|}
\hline & \multicolumn{2}{|c|}{ QALY } & \multicolumn{2}{|c|}{$\begin{array}{c}\text { Net costs } \\
\text { (2011 NZ\$ million) } \dagger\end{array}$} & \multirow{2}{*}{$\begin{array}{c}\text { ICER } \\
\text { (2011 \$NZ per QALY gained) }\end{array}$} \\
\hline & Estimate & $95 \%$ UI & Estimate & $95 \%$ UI & \\
\hline Sex and age groups combined & 250 & $-70,560$ & 33.9 & $24 \cdot 1,43 \cdot 8$ & 138200 \\
\hline Males & 140 & $-90,390$ & $16 \cdot 3$ & $10 \cdot 1,22 \cdot 2$ & 119700 \\
\hline Females & 110 & $-70,320$ & $17 \cdot 6$ & $12 \cdot 3,22 \cdot 9$ & 161400 \\
\hline Non-Māori & 200 & $-110,510$ & $28 \cdot 8$ & $20 \cdot 1,37 \cdot 7$ & 143000 \\
\hline Māori & 40 & $-20,120$ & $5 \cdot 1$ & $3 \cdot 4,6 \cdot 7$ & 116000 \\
\hline Māori - equitył & 60 & $-20,150$ & $5 \cdot 1$ & $3 \cdot 3,6 \cdot 7$ & 90700 \\
\hline
\end{tabular}

UI, uncertainty interval; ICER, incremental cost-effectiveness ratio.

Results rounded to either two or three meaningful digits.

*Results are modelled using $3 \%$ discounting and include QALY for over 25-year-olds as relative risks for the associations between risk factors and disease start at age 25 years.

tIncludes both the cost offsets and dietary counselling intervention costs (see ${ }^{1}$ for details), distributed pro rata across all people alive in 2011 . Intervention costs were partitioned by age, sex and ethnicity.

‡QALY calculated using non-Māori background mortality and morbidity rates ${ }^{(25)}$.

Table 3 Sensitivity and scenario analyses about health gains and net health-system costs among the New Zealand (NZ) adult population for the weight-loss counselling intervention delivered by practice nurses in primary-care settings*

\begin{tabular}{|c|c|c|c|}
\hline Scenario & $\begin{array}{l}\text { QALY } \\
\text { gained }\end{array}$ & $\begin{array}{l}\text { Net costs } \\
(2011 \$ N Z \\
\text { million)† }\end{array}$ & $\begin{array}{c}\text { ICER } \\
\text { (2011 NZ\$ } \\
\text { per QALY } \\
\text { gained) }\end{array}$ \\
\hline 'Base' caseł & 250 & 33.7 & 133400 \\
\hline $\begin{array}{l}\text { Discount rate: } 0 \% \text { per } \\
\text { annum }\end{array}$ & 410 & $32 \cdot 7$ & 79800 \\
\hline $\begin{array}{l}\text { Discount rate: } 6 \% \text { per } \\
\text { annum }\end{array}$ & 170 & 34.5 & 201800 \\
\hline $\begin{array}{l}\text { Non-scaled effect size } \\
\text { in meta-analysis } \\
(3 \% \text { discount rate })^{(4)}\end{array}$ & 330 & $32 \cdot 3$ & 96400 \\
\hline $\begin{array}{l}\text { No decay in weight-loss } \\
\text { benefit subsequently } \\
\text { (3\% discount rate) }\end{array}$ & 9670 & $-140 \cdot 1$ & Dominant \\
\hline
\end{tabular}

QALY, quality-adjusted life-year; ICER, incremental cost-effectiveness ratio. Results rounded to either two or three meaningful digits.

*Expected value analysis, no uncertainty.

†Includes both the cost offsets and dietary counselling intervention costs (see Table 1 for details), distributed pro rata across all people alive in 2011.

fDiscount rate $3 \%$, modelled $\mathrm{BMI}$ reduction decays back to the pre-intervention $\mathrm{BMI}$ at a rate of 0.03 units per month returning to approximately baseline levels the year after the intervention.

likelihood that this intervention will be cost-effective against various levels of governmental willingness-topay. If willingness-to-pay is set to the level of gross domestic product per capita per QALY gained (i.e. 2011 \$NZ 45000 or 2018 \$US 33 400), the probability that the intervention would be cost-effective was $2 \%$.

Per capita QALY gains were 0.06 QALY per 1000 adults in the population as a whole and $0 \cdot 22$ QALY per 1000 adults in the target population. Per capita gains were 1.40 times higher for Māori (0.07/1000 people) than for non-Māori (0.05/1000 people) but twice as high when using age standardisation (based on age in 2011), assuming that the intervention achieved equal coverage within age groups, was equally effective and had the same attenuation for Māori and non-Māori. For the target population (obese and overweight), age-standardised per capita gains for Māori were 2.33 times greater than those for non-Māori. The Māori-equity analysis increased modelled Māori health gains by 12 QALY ( $27 \%$ over the default analysis) and gave a greater per capita ratio in the total population for Māori compared with nonMāori (1.60 crude ratio, 2.50 when age-standardised).

In a sensitivity analysis, when the model was rerun with no discounting, QALY gains increased to approximately 410 QALY and costs decreased to 2011 \$NZ 32.7 milliion (Table 3). In contrast, at a discount rate of $6 \%$, these results were 170 QALY and 2011 \$NZ 34.5 million. In the scenario analysis when weight-loss decay was switched off, simulating a theoretical situation where all weight lost with the intervention was maintained over the subsequent course of the participants' lifetimes, the QALY gains increased 39-fold to 9670 QALY and the intervention became cost-saving at 2011 \$NZ 140.1 million (all at the 3\% discount rate).

Parameters contributing to the uncertainty in the model are shown in Fig. 4 and Supplemental Figs S1 and S2. The parameter that contributed the most to the uncertainty around the NMB, health gain (QALY) and health-system cost was the intervention effect size. For QALY, the next most important contributors to the uncertainty were: whether participants are referred to the intervention; the relative risks for BMI and disease incidence; and the proportion of those taking up the intervention, i.e. those 'exposed to the intervention'. Intervention costs contributed substantially to the uncertainty around total costs, followed by whether participants were referred to the intervention, the relative risks for the relationship between BMI and disease, and health-system costs. For NMB the next most significant contributors to uncertainty after the effect size were the intervention costs, whether participants are referred to the practice-nurse-delivered intervention by GPs, and the relative risks for the relationship between BMI and disease incidence. 


\section{Discussion}

\section{Main findings and interpretation}

The total estimated health gain from this modelled intervention in the NZ population was relatively small, at about 250 QALY. There was only a low chance that dietary counselling, in its modelled form, would be cost-effective compared with no intervention; that is, a $2 \%$ chance if willingness-to-pay was set to a gross domestic product per capita level per QALY gained (2011 \$NZ 45000 or 2018 \$US 33 400).

Per capita gains were higher for Māori than for non-Māori as a result of a higher prevalence of elevated BMI, a higher burden of diseases modifiable through BMI change and the extended age range of intervention eligibility for Māori (e.g. from 35 years instead of 45 years for males as per current NZ guidelines; see the 'Methods' section). It was assumed that uptake and effectiveness of the counselling were the same by ethnicity; if these were lower for Māori then the overall health gains for Māori would be less.

The relatively small health gain seen at a population level with this intervention is common for weight-loss interventions and other treatment interventions that target individuals. The small effect size among participants of $0.34 \mathrm{~kg}$ found in the studies included in the meta-analysis by Hartman-Boyce et al. ${ }^{(4)}$ reduced to a change in BMI of only 0.03 units per eligible person in the overweight/obese NZ population. This small change in BMI translated to per capita QALY gains of 0.06 QALY per 1000 adults in the population as a whole and 0.22 QALY per 1000 adults for the target population.

\section{Study strengths and limitations}

The evidence used in this modelling was for the effect of behavioural weight-management programmes for adults conducted in everyday contexts. This was appropriate as it covered structured weight-management programmes incorporating diet, physical activity and a behaviour change strategy that would be appropriate for the counselling intervention described in the present study. The metaanalysis was for primary-care interventions using staff already based in the general practice in four out of five studies and trained lay people in the additional study, rather than practice nurses specifically. The interventions in the meta-analysis also involved multiple contacts. This partially lines up with the modelled intervention, which was based on one main initial contact and then follow-up as necessary by telephone, text message, email or in person. An additional strength is that the effect size has been scaled to line up with the amount of contact time estimated in the modelled intervention.

We assumed all the training, intervention and costs occur in 1 year and that these costs were met by the health system for ease of modelling. This modelling scenario is somewhat hypothetical as it may not be entirely feasible to rapidly upscale nurse weight-loss counselling and deliver the intervention in just year one (without some spill-over into year two), and similarly it would be unlikely to 'be turned off' again after 1 year. If this intervention was repeated annually, this would cover many of the same individuals so the pool of eligible individuals would decrease over time but it would capture those who are newly screened. Some individuals who refused the intervention in the first year may decide to take it up in subsequent years. It is likely that this approach would increase health gains but it is difficult to estimate the impact on the costeffectiveness of the intervention.

This intervention has proposed using the 'Heart and Diabetes Checks ${ }^{(20)}$ national programme currently running in NZ to recruit overweight and obese adults to this intervention. This programme targets specific age groups (see the 'Methods' section for details) and captures $90 \%$ of its target population. Using this approach has allowed this theoretical intervention to capture a high proportion of the target population, a level that may be difficult to successfully attract into the dietary counselling intervention if rolled out in NZ.

The intervention was modelled solely through a change in BMI but ignores other effects the intervention might generate. The interventions included in the meta-analysis included advice to increase physical activity but the change in metabolic equivalents of task is not captured in the metaanalysis or in the modelling. There may also be an improvement in other dietary risk factors such as increased fruit and vegetable intake or reduced sodium and sugar intakes which are not captured. Nor does the intervention include the possibility that some practice nurses might provide advice to patients on using smartphone apps for dietary change or using pedometer functions on smartphones, for which there is growing evidence for effectiveness ${ }^{(26,27)}$. Our results may therefore include an element of underestimation of the health benefit.

The base year for demographic, epidemiological and costing specification is 2011, with trends out to 2026 - as per other evaluations in the Burden of Disease Epidemiology, Equity and Cost-Effectiveness (BODE ${ }^{3}$ ) Programme from which this evaluation arises. This allows useful comparisons with other interventions. It was beyond the scope of this evaluation to update the entire model to a more recent base year such as 2018. Had this been done, we anticipate the total health gain in QALY would have increased slightly due to population growth and ongoing high obesity rates, but the general pattern of findings would change little.

\section{Potential implications for research and bealth agencies}

The results of this modelling suggest that the majority of the uncertainty in the health gain and costs from this intervention was due to the uncertainty of the intervention effect size. 
Indeed, the effect size used was based on only five studies and the associated confidence interval was wide. Therefore more high-quality, large research projects into the effectiveness of dietary counselling for weight loss may be desirable. Alternatively the health sector could invest more in other evaluated obesity-prevention and management interventions ahead of counselling ones (including those listed for Australia and NZ in an online league table of methodologically compatible interventions $\left.{ }^{(28)}\right)$. For example, Retat et $a l^{(29)}$ found that physicians referring overweight people to a weight-loss programme generated health gains and cost savings compared with providing weight-loss advice directly. There is also some evidence that is starting to favour other strategies which address the obesogenic environment (e.g. taxes on sugary drinks and junk foods as used in Mexico ${ }^{(30)}$, food marketing controls $^{(31)}$, healthy school lunch programmes ${ }^{(32)}$ etc.). Indeed, modelling work conducted in Australia has found a range of obesity-prevention interventions to be either cost-saving (eleven interventions) or cost-effective (five interventions) ${ }^{(33)}$. The interventions generating the most health gains and cost savings were a volumetric tax on alcohol, taxing sugar-sweetened beverages and restricting television advertising of unhealthy foods.

\section{Conclusions}

The present study provides modelling-level evidence for the likely impact of counselling for weight loss delivered by practice nurses in the primary-care setting. Despite brief dietary counselling in primary care being commonly recommended within health systems, our evaluation suggests that this intervention generates a relatively small health gain at the population level and is unlikely to be cost-effective. Although per capita gains were higher for Māori than for non-Māori, based on the incremental costeffectiveness ratio results dietary counselling was still unlikely to be cost-effective for Māori.

\section{Acknowledgements}

Acknowledgements: The authors thank June Atkinson for generating the disease cost data and Kendra Telfer for extracting data on the individual studies from the review paper used for the effect size; Kirsten Coppell for her advice on dietary counselling in NZ; Alison Pask and Dietitians NZ for their advice about the training of the practice nurses; and Graeme Campbell from the Ministry of Health for information on the number of primary health organisations/'GP practices' submitting enrolment registers. Financial support: This research was funded by the Ministry of Business Innovation \& Employment (MBIE; project number UOOX1406). The authors are supported by the BODE $^{3}$ Programme which is studying the effectiveness and cost-effectiveness of various preventive interventions and receives funding support from the Health Research Council of New Zealand (project number 10/248). Neither the MBIE or the Health Research Council of New Zealand had any role in the design, analysis or writing of this article. Conflict of interest: None. Authorship: C.L.C. transformed the existing tobacco MSLT to model dietary risk factors, helped conceptualise the intervention, modelled the intervention and wrote the first draft of the paper. N.W. conceived of the idea, helped conceptualise the intervention and contributed to drafts of the paper. N.Na. helped conceptualise the intervention and contributed to drafts of the paper. M.M. contributed to the equity analyses and contributed to drafts of the paper. G.K. and N.Ng. contributed to the model build and to drafts of the paper. T.B. contributed to the model build, helped conceptualise the intervention and contributed to drafts of the paper. Ethics of buman subject participation: This was a simulation study using administratively collected data on the whole NZ population and does not involve direct data collection on human participants.

\section{Supplementary material}

To view supplementary material for this article, please visit https://doi.org/10.1017/S1368980019002945

\section{References}

1. Lim SS, Vos T, Flaxman AD et al. (2013) A comparative risk assessment of burden of disease and injury attributable to 67 risk factors and risk factor clusters in 21 regions, 1990-2010: a systematic analysis for the Global Burden of Disease Study 2010. Lancet 380, 2224-2260.

2. Forouzanfar MH, Alexander L, Anderson HR et al. (2015) Global, regional, and national comparative risk assessment of 79 behavioural, environmental and occupational, and metabolic risks or clusters of risks in 188 countries, 1990-2013: a systematic analysis for the Global Burden of Disease Study 2013. Lancet 386, 2287-2323.

3. Ministry of Health (2010) Implementing the Clinical Guidelines for Weight Management in New Zealand 2010/ 11. Wellington: Ministry of Health.

4. Hartmann-Boyce J, Johns DJ, Jebb SA et al. (2014) Behavioural weight management programmes for adults assessed by trials conducted in everyday contexts: systematic review and meta-analysis. Obes Rev 15, 920-932.

5. Franz MJ, VanWormer JJ, Crain AL et al. (2007) Weight-loss outcomes: a systematic review and meta-analysis of weightloss clinical trials with a minimum 1-year follow-up. J Am Diet Assoc 107, 1755-1767.

6. Dansinger ML, Tatsioni A, Wong JB et al. (2007) Meta-analysis: the effect of dietary counseling for weight loss. Ann Intern Med 147, 41-50.

7. Brown I \& Psarou A (2008) Literature review of nursing practice in managing obesity in primary care: developments in the UK. J Clin Nurs 17, 17-28.

8. Sargent G, Forrest L \& Parker R (2012) Nurse delivered lifestyle interventions in primary health care to treat chronic disease risk factors associated with obesity: a systematic review. Obes Rev 13, 1148-1171. 
9. Segal L, Dalton AC \& Richardson J (1998) Cost-effectiveness of the primary prevention of non-insulin dependent diabetes mellitus. Health Promot Int 13, 197-209.

10. Gillett M, Royle P, Snaith A et al. (2012) Non-pharmacological interventions to reduce the risk of diabetes in people with impaired glucose regulation: a systematic review and economic evaluation. Health Technol Assess 16, $1-236$.

11. Forster M, Veerman J, Barendregt J et al. (2011) Costeffectiveness of diet and exercise interventions to reduce overweight and obesity. Int J Obes (Lond) 35, 1071-1078.

12. Blakely T, Cobiac LJ, Cleghorn CL et al. (2015) Health, health inequality, and cost impacts of annual increases in tobacco tax: multistate life table modeling in New Zealand. PLoS Med 12, e1001856.

13. Pearson AL, Cleghorn CL, van der Deen FS et al. (2017) Tobacco retail outlet restrictions: health and cost impacts from multistate life-table modelling in a national population. Tob Control 26, 579-585.

14. Van der Deen FS, Wilson N, Cleghorn CL, et al. (2018) Impact of five tobacco endgame strategies on future smoking prevalence, population health and health system costs: two modelling studies to inform the tobacco endgame. Tob Control 27, 278-286.

15. Cleghorn CL, Blakely T, Kvizhinadze G et al. (2018) Impact of increasing tobacco taxes on working-age adults: short-term health gain, health equity and cost savings. Tob Control 27, e167-e170.

16. Cleghorn C, Wilson N, Nair N et al. (2018) Health benefits and cost-effectiveness from promoting smartphone apps for weight loss: multi-state life-table modeling. JMIR Mhealth Uhealth 7, e11118.

17. Cleghorn C, Blakely T, Mhurchu CN et al. (2019) Estimating the health benefits and cost-savings of a cap on the size of single serve sugar-sweetened beverages. Prev Med 120, 150-156.

18. Cleghorn C, Blakely T, Nghiem N et al. (2017) Technical Report for BODE Intervention and Diet MSLT models, Version 1. Burden of Disease Epidemiology, Equity and Cost-Effectiveness Programme (BODE $\left.{ }^{3}\right)$. Technical Report no. 16. Wellington: University of Otago.

19. University of Otago \& Ministry of Health (2011) A Focus on Nutrition: Key Findings of the 2008/09 New Zealand Adult Nutrition Survey. Wellington: Ministry of Health.

20. Ministry of Health (2014) Heart and diabetes checks. http:// www.health.govt.nz/your-health/conditions-and-treatments/ diseases-and-illnesses/heart-disease/heart-and-diabetes-checks (accessed October 2017)

21. New Zealand Ministry of Health (2016) Health targets - 2015/ 16 quarter 1 - results summary. http://www.health.govt.nz/ new-zealand-health-system/health-targets/how-my-dhbperforming/how-my-dhb-performing-2015-16/health-targets2015-16-quarter-1-results-summary (accessed May 2017).
22. Brotons C, Ciurana R, Piñeiro R et al. (2003) Dietary advice in clinical practice: the views of general practitioners in Europe. Am J Clin Nutr 77, 4 Suppl., 1048S-1051S.

23. Wee CC, Davis RB \& Phillips RS (2005) Stage of readiness to control weight and adopt weight control behaviors in primary care. J Gen Intern Med 20, 410-415.

24. Barendregt J (2012) Ersatz User Guide. Sunrise Beach, QLD: EpiGear International Pty Ltd.

25. McLeod M, Blakely T, Kvizhinadze G et al. (2014) Why equal treatment is not always equitable: the impact of existing ethnic health inequalities in cost-effectiveness modeling. Popul Health Metr 12, 15.

26. Flores Mateo G, Granado-Font E, Ferré-Grau C et al. (2015) Mobile phone apps to promote weight loss and increase physical activity: a systematic review and meta-analysis. J Med Internet Res 17, e253.

27. Kang M, Marshall SJ, Barreira TV et al. (2009) Effect of pedometer-based physical activity interventions: a metaanalysis. Res Q Exercise Sport 80, 648-655.

28. University of Otago \& University of Melbourne (2019) ANZHILT: Australia and New Zealand Health Intervention League Table (Vers 2.0). https://league-table.shinyapps.io/bode3/ (accessed September 2019).

29. Retat L, Pimpin L, Webber L et al. (2019) Screening and brief intervention for obesity in primary care: cost-effectiveness analysis in the BWeL trial. Int J Obes (Lond). Published online: 31 January 2019. doi: 10.1038/s41366-018-0295-7.

30. Colchero MA, Rivera-Dommarco J, Popkin BM et al. (2017) In Mexico, evidence of sustained consumer response two years after implementing a sugar-sweetened beverage tax. Health Aff (Millwood) 36, 564-571.

31. Dhar T \& Baylis K (2011) Fast-food consumption and the ban on advertising targeting children: the Quebec experience. J Mark Res 48, 799-813.

32. Spence S, Delve J, Stamp E et al. (2013) The impact of food and nutrient-based standards on primary school children's lunch and total dietary intake: a natural experimental evaluation of government policy in England. PLoS One 8, e78298.

33. Ananthapavan J SG, Brown V, Moodie M et al. (2018) Assessing Cost-Effectiveness of Obesity Prevention Policies in Australia 2018 (ACE-Obesity Policy). Melbourne: Deakin University.

34. New Zealand Medical Association (2012) Old Primary Health Care MECA 2010-2012. https://www.nzma.org.nz/ membership/primary-health-care-meca (accessed September 2019).

35. Wilson N (2014) Technical Report: Estimating the Modelling Parameters Around Dietary Counselling for Preventing Cardiovascular Disease in New Zealand. Wellington: University of Otago.

36. Foster R, Blakely T, Wilson N et al. (2012) Protocol for Direct Costing of Health Sector Interventions for Economic Modelling: Including Event Pathways. Wellington: Department of Public Health, University of Otago. 